\title{
Effects of Exercise Intensity and Altered Substrate Availability on Cardiovascular and Metabolic Responses to Exercise After Oral Carnitine Supplementation in Athletes
}

\author{
Elizabeth M. Broad, Ronald J. Maughan, and Stuart D.R. Galloway
}

\begin{abstract}
The effects of $15 \mathrm{~d}$ of supplementation with L-carnitine L-tartrate (LC) on metabolic responses to gradedintensity exercise under conditions of altered substrate availability were examined. Fifteen endurance-trained male athletes undertook exercise trials after a 2-d high-carbohydrate diet $(60 \% \mathrm{CHO}, 25 \%$ fat $)$ at baseline (D0), on Day 14 (D14), and after a single day of high fat intake (15\% CHO, $70 \%$ fat) on Day 15 (D15) in a

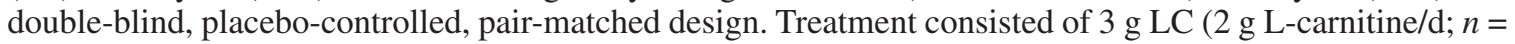
8) or placebo (P, $n=7)$ for $15 \mathrm{~d}$. Exercise trials consisted of $80 \mathrm{~min}$ of continuous cycling comprising 20-min periods at each of $20 \%, 40 \%, 60 \%$, and $80 \% \mathrm{VO}_{2 \text { peak }}$. There was no significant difference between whole-body rates of CHO and fat oxidation at any workload between D0 and D14 trials for either the P or LC group. Both groups displayed increased fat and reduced carbohydrate oxidation between the D14 and D15 trials $(p<.05)$. During the D15 trial, heart rate ( $p<.05$ for 20\%, 40\%, and 60\% workloads) and blood glucose concentration ( $p<.05$ for $40 \%$ and $60 \%$ workloads) were lower during exercise in the LC group than in P. These responses suggest that LC may induce subtle changes in substrate handling in metabolically active tissues when fattyacid availability is increased, but it does not affect whole-body substrate utilization during short-duration exercise at the intensities studied.
\end{abstract}

Keywords: L-carnitine L-tartrate, cyclists, fat oxidation, carbohydrate oxidation

L-carnitine (LC) plays a role in fat metabolism through its function as a transporter of long-chain fatty acids into mitochondria for $\beta$-oxidation (Fritz, 1963), and it also acts to buffer excess mitochondrial acetyl-CoA by forming acetylcarnitine. Thus, carnitine is involved in the integration of carbohydrate $(\mathrm{CHO})$, amino acid, and fat metabolism, making it a key metabolic regulator both in skeletal muscle (Roepstorff et al., 2005; van Loon, Greenhaff, Constantin-Teodosiu, Saris, \& Wagenmakers, 2001) and in other important metabolically active tissues such as heart, brain, pancreas, and liver (Broderick et al., 1995; Harper, Wadstrom, Backman, \& Cederblad, 1995; Hino, Nishikawa, Sato, \& Inoue, 2005; Kai et al., 2005).

We have previously observed metabolic changes during cycling exercise at $60 \%$ of $\mathrm{VO}_{2 \text { peak }}$ in endurancetrained males after 2 weeks of LC supplementation, including an increase in whole-body $\mathrm{CHO}$ oxidation and a tendency toward blunted ammonia accumulation

Broad is with Sports Nutrition, Australian Institute of Sport, Canberra, Australia. Maughan is with the School of Sport and Exercise Sciences, Loughborough University, Leicestershire, UK. Galloway is with the School of Sport, University of Stirling, Scotland, UK. during exercise (Abramowicz \& Galloway, 2005; Broad, Maughan, \& Galloway, 2008). Furthermore, substrate selection in cardiac muscle has been observed to shift toward $\mathrm{CHO}$ metabolism when large increases in carnitine availability are induced (Lopaschuk, 2000) but also with increases in carnitine within the physiological range (Rodgers, Christe, Tremblay, Babson, \& Daniels, 2001). Hyperinsulinemic-euglycemic-clamp studies show increased glucose disposal after carnitine supplementation in controls and patients with Type 2 diabetes (Ferrannini et al., 1988; Giancaterini et al., 2000; Mingrone et al., 1999), and carnitine infusion during a clamp results in increased muscle glycogen storage (Stephens, Constantin-Teodosiu, Laithwaite, Simpson, \& Greenhaff, 2006). These data suggest that carnitine can increase glucose disposal at rest and stimulate glucose oxidation during contractile activity without necessarily altering skeletal-muscle total carnitine content. However, it is also known that an elevation in skeletal-muscle carnitine after oral LC supplementation is achievable in humans, especially if the LC is consumed in combination with adequate CHO (Stephens, Evans, Constantin-Teodosiu, \& Greenhaff, 2007; Wall et al., 2010).

The numerous attempts that have been made to determine whether LC supplementation can influence whole-body substrate selection at rest and during 
exercise have produced varying results (for reviews see Brass \& Hiatt, 1998; Galloway \& Broad, 2005; Karlic \& Lohninger, 2004; Stephens, Constantin-Teodosiu, \& Greenhaff, 2007). The reasons for the variability in results are not fully understood but may relate to differences in exercise intensity, prior dietary intake, or training status of the subjects.

Exercise intensity determines the proportion of different fuels used for energy supply, with exercise at low intensity relying predominantly on plasma free fatty acids (FFA) as a source of fuel (Romijn et al., 1993). Recently it has been shown that the effect of oral carnitine supplementation on substrate metabolism varies with exercise intensity (Wall et al., 2010). Therefore, previous studies, including our own, that have investigated the effects of LC supplementation at relatively high fixed exercise intensities $\left(>60 \% \mathrm{VO}_{2 \max }\right)$ with high $\mathrm{CHO}$ availability (CHO replete during supplementation period, $\mathrm{CHO}-$ based pretrial meal) may have restricted the ability to detect an impact of LC supplementation on metabolism during exercise.

Preexercise substrate availability is also known to influence substrate utilization during exercise. However, only one study (Decombaz, Deriaz, Acheson, Gmuender, \& Jequier, 1993) previously examined manipulations in substrate availability before exercise with and without supplemental carnitine. Decombaz et al. examined the effects of an overnight fast and the effect of glycogendepleting exercise on substrate metabolism in healthy active males with and without 7 days of LC supplementation. They observed no changes in substrate use or heartrate response to exercise in either the overnight-fasted state or the glycogen-depleted state. Studies conducted at rest with intralipid and heparin infusion to acutely elevate plasma FFA also indicate no impact of LC infusion on basal substrate metabolism (Natali et al., 1993), but to date no study has examined the impact of manipulating exercise intensity and acutely increasing the availability of circulating FFA through the ingestion of high-fat meals on the metabolic response to exercise after LC supplementation.

Therefore, this study aims to further examine the effects of LC supplementation on substrate metabolism during exercise by examining the metabolic response at different intensities under conditions of altered substrate availability in well-trained subjects. We hypothesized that this approach could provide some insight into the potential effects of LC supplementation on whole-body substrate selection during exercise in athletes and lead to a better understanding of this supplement's practical applications.

\section{Methods}

Sixteen nonvegetarian male athletes actively involved in endurance training, all with a $\mathrm{VO}_{2 \text { peak }}$ greater than $50 \mathrm{ml} \cdot \mathrm{kg}^{-1} \cdot \mathrm{min}^{-1}$, were recruited. One subject was unable to complete the study because of illness, so characteristics shown in Table 1 are for 15 subjects. All subjects were fully informed about the study, provided written informed consent, and underwent preparticipation screening (medical history and physical activity questionnaires). The study was undertaken during the preparation phase of the cycling and triathlon competitive season to ensure that consistent endurance-based training was being undertaken and to avoid a training effect. All experimental procedures were approved by the university Ethics of Research Committee, and all subjects were free to withdraw from the study at any time without obligation.

The study used a double-blind, placebo-controlled, pair-matched parallel design based on our previous work indicating that plasma total carnitine concentration did not return to baseline for up to 4 weeks after cessation of oral supplementation (Broad et al., unpublished observations). Pair matching was undertaken primarily on the basis of training history, exercise workload at $\mathrm{VO}_{2 \text { peak }}$, and age. Subjects came to the laboratory on five occasions over 4-5 weeks. The first visit was used to determine $\mathrm{VO}_{\text {2peak }}$ using an incremental cycle protocol after a 3-min warm-up, which commenced at $150 \mathrm{~W}$ and increased $30 \mathrm{~W}$ every 3 min until the subject could no longer maintain a cadence over $70 \mathrm{rpm}$. When a full 3 min was not completed at the final workload, $10 \mathrm{~W}$ was added to the previously completed workload for each full minute accomplished to calculate the power output at $\mathrm{VO}_{2 \text { peak. }}$. Body composition was assessed using the sum of seven skinfold measures (biceps, triceps, subscapular, supraspinale, abdomen, midthigh, and calf; mean of duplicate measures; Norton \& Olds, 2000). All exercise trials were undertaken on a Lode Excalibur Sport V2.1 ergometer (Lode BV, The Netherlands) set up to the athletes' training-bike measurements, with the athletes using their own pedals and shoes, in a laboratory where the temperature was maintained at $20-21{ }^{\circ} \mathrm{C}$. All subjects then undertook one familiarization trial to ensure that loads of $20 \%, 40 \%, 60 \%$, and $80 \%$ of $\mathrm{VO}_{2 \text { peak }}$ had been selected appropriately and to familiarize subjects with

Table 1 Subject Characteristics, $M \pm S D$

\begin{tabular}{lcc}
\hline Variable & $\begin{array}{c}\text { Placebo } \\
(\boldsymbol{n}=\mathbf{7})\end{array}$ & $\begin{array}{c}\text { LC } \\
(\boldsymbol{n}=\mathbf{8})\end{array}$ \\
\hline Age (years) & $31 \pm 8$ & $34 \pm 10$ \\
Height (cm) & $177 \pm 5$ & $181 \pm 4$ \\
Body mass (kg) & $73.5 \pm 10.3$ & $77.3 \pm 7.7$ \\
Skinfolds (sum of 7, mm) & $61.5 \pm 17.4$ & $67.7 \pm 31.6$ \\
VO $_{2 \text { max }}(\mathrm{L} / \mathrm{min})$ & $5.09 \pm 0.43$ & $4.93 \pm 0.56$ \\
Current cycle training (hr/ $_{\text {week) }}$ & $7.4 \pm 2.7$ & $6.1 \pm 2.3$ \\
20\% workload (W) & $71 \pm 7$ & $68 \pm 9$ \\
40\% workload (W) & $141 \pm 12$ & $137 \pm 18$ \\
60\% workload (W) & $211 \pm 18$ & $205 \pm 28$ \\
80\% workload (W) & $282 \pm 24$ & $273 \pm 37$ \\
\hline
\end{tabular}

Note. $\mathrm{LC}=\mathrm{L}$-carnitine. 
testing procedures. If subjects were found to be working at an inappropriate load, this was adjusted before completing the subsequent trials. All subsequent trials were undertaken at the same time of day.

\section{Treatment}

After the familiarization trial, subjects were pair-matched for allocation to active treatment with L-carnitine L-tartrate (LC) or placebo (P). Subjects then attended the laboratory at the following times: baseline measurements before treatment commenced (D0), after 14 days supplementation (D14), and $24 \mathrm{hr}$ later after high fat intake (D15). Treatments consisted of two capsules taken twice daily with meals (i.e., four capsules per day total) for 15 days. The supplement capsule consisted of $746 \mathrm{mg}$ of LC (L-carnipure, Lonza Ltd., Basel, Switzerland), thereby providing $3 \mathrm{~g}$ LC per day, equivalent to $2 \mathrm{~g} \mathrm{~L}$-carnitine per day ( $3 \mathrm{~g}$ L-carnitine L-tartrate provides $2 \mathrm{~g}$ L-carnitine). The placebo capsule consisted of a methyl cellulose filler of the same weight as the carnitine. Subjects' compliance to the treatment was assessed by checking whether any capsules remained at the end of 15 days, with no evidence of noncompliance found.

\section{Dietary and Exercise Controls}

Each subject was prescribed a dietary intake for 48 $\mathrm{hr}$ before the D0 and D14 trials based on attaining an energy ratio of $60 \% \mathrm{CHO}, 15 \%$ protein, and $25 \%$ fat and achieving estimated energy requirements (Burke, 1996). These 2-day diets were designed around subjects' typical dietary intake taken from a 7-day food diary. In the $24 \mathrm{hr}$ between the D14 and D15 trials, subjects were provided with all the food they were to consume. This high-fat, low-CHO intake was individualized from two standard menus (Table 2) and designed to provide the same total energy as the previously prescribed diets in an energy ratio of $15 \% \mathrm{CHO}, 15 \%$ protein, and $70 \%$ fat. Compliance was assessed on trial days by using a checklist of the foods prescribed in the $48 \mathrm{hr}$ before D0 and D14 trials and of the foods provided in the $24 \mathrm{hr}$ before the D15 trial. Subjects were also asked to undertake the same exercise in the $48 \mathrm{hr}$ before the D0 and D14 trials. Water was allowed ad libitum throughout each dietary period. Between the initial trials on D0 and the start of the dietary control for the D14 trial, subjects resumed their habitual dietary intake.

\section{The Trials}

A 24-hr urine collection was undertaken before trial commencement on D0 and D14. All trials were undertaken 3 $\mathrm{hr}$ after ingestion of the last supplement, which was taken with a standardized meal. For the trials on D0 and D14, this consisted of $1 \mathrm{~g} / \mathrm{kg}$ body mass (BM) $\mathrm{CHO}$ (bread and jam) and, for the high-fat trial, whole milk with added cream to match the energy and protein content of D0 and D14 while preserving the ratios of $70 \%$ fat, $15 \% \mathrm{CHO}$. On arrival at the laboratory, nude BM (NBM) was assessed, a heart-rate monitor positioned, and a cannula (20-gauge, SSS Healthcare) inserted into an antecubital vein. After 5 min of seated rest a blood sample was drawn without stasis, along with a free-flowing capillary sample from a preheated hand for analysis of $\mathrm{pH}, \mathrm{pCO}_{2}$, and bicarbonate (Radiometer ABL 700, Copenhagen, Denmark). The cannula was kept patent at all times using a 1-ml saline flush after sample collections. Subjects then mounted the cycle ergometer, where they were equipped with a mouthpiece and nose clip for measurement of expired gas (4 min at rest).

Subjects began cycling for $20 \mathrm{~min}$ at $20 \%$ of power output at $\mathrm{VO}_{2 \text { peak }}$, followed in a continuous fashion by 20 min each at $40 \%, 60 \%$, and $80 \%$ of power output at $\mathrm{VO}_{2 \text { peak }}(80 \mathrm{~min}$ total), at a self-selected pedal cadence (mean for P group $95 \mathrm{rpm}$, and for LC group, $89 \mathrm{rpm}$ ). Expired-gas analysis was undertaken during the last 4 min of each 20-min workload plus midway through the final workload to estimate rates of $\mathrm{CHO}$ and fat oxidation (Peronnet \& Massicotte, 1991). Heart rate (HR) was recorded at 60-s intervals throughout the trial (PolarVantage, NV, Finland) and a rating of perceived exertion (15-point Borg scale; Borg, 1982) recorded every $10 \mathrm{~min}$ throughout exercise. Capillary and venous blood samples were drawn at rest and at the end of each workload. Water was provided throughout the trial, with encouragement to achieve sufficient fluid intake to prevent dehydration, based on volume consumed and the change in body mass observed in the familiarization trial. Subjects were cooled with a fan throughout all trials to limit thermal stress.

Table 2 The Two Standard Menus Used to Create the 24-hr High Fat Intake for Each Individual

\begin{tabular}{|c|c|c|}
\hline Time of day & Menu 1 & Menu 2 \\
\hline Posttrial snack & Peanuts $(50 \mathrm{~g})$ and crisps $(25 \mathrm{~g})$ & Peanuts $(50 \mathrm{~g})$ and crisps $(25 \mathrm{~g})$ \\
\hline Lunch & $\begin{array}{l}\text { Garden salad with } 100 \mathrm{~g} \text { avocado, } 100 \mathrm{~g} \text { coleslaw, } \\
30 \mathrm{~g} \text { salad dressing, and } 150 \mathrm{~g} \text { roast chicken with skin }\end{array}$ & $\begin{array}{l}\text { Garden salad with } 100 \mathrm{~g} \text { avocado, } 100 \mathrm{~g} \text { coleslaw, } 30 \mathrm{~g} \\
\text { salad dressing, } 100 \mathrm{~g} \text { ham, } 100 \mathrm{~g} \text { cheese }\end{array}$ \\
\hline Midafternoon & 60-g Mars bar, celery with $60 \mathrm{~g}$ sour-cream-based dip & 60-g Mars bar, celery with 60 g sour-cream-based dip \\
\hline Dinner & $\begin{array}{l}200 \mathrm{ml} \text { cream-of-chicken soup; } 170 \text {-g beef steak and } \\
\text { onion fried in } 30 \mathrm{ml} \text { olive oil with broccoli, carrot, } \\
\text { cauliflower; chocolate mousse with } 50 \mathrm{ml} \text { cream }\end{array}$ & $\begin{array}{l}200 \mathrm{ml} \text { cream-of-chicken soup; } 170 \mathrm{~g} \text { chicken Kiev } \\
\text { with broccoli, carrot, cauliflower; chocolate mousse } \\
\text { with } 50 \mathrm{ml} \text { cream }\end{array}$ \\
\hline Pretrial snack & $300 \mathrm{ml}$ whole milk with $50 \mathrm{ml}$ cream & $300 \mathrm{ml}$ whole milk with $50 \mathrm{ml}$ cream \\
\hline
\end{tabular}


After completing the $80 \mathrm{~min}$, subjects rested during the removal of the cannula, towel-dried, and then recorded their final NBM.

\section{Blood and Urine Analysis}

Venous blood ( $2.5 \mathrm{ml}$ ) was drawn at rest and every $20 \mathrm{~min}$ during exercise. Duplicate 100- $\mu 1$ aliquots of whole blood were immediately deproteinized in $1 \mathrm{ml}$ chilled $0.4-\mathrm{M}$ perchloric acid, shaken vigorously, and kept on ice until centrifugation at 10,000 rpm for $3 \mathrm{~min}$. Samples were subsequently frozen at $-20^{\circ} \mathrm{C}$ until analysis. Blood lactate (Maughan, 1982) and glycerol (Boobis \& Maughan, 1983) concentrations were measured by fluorometric enzymatic assays (Jenway 6200 fluorimeter, Jenway Ltd., Essex). The remaining blood was mixed well in EDTA tubes, and duplicate samples were drawn into capillary tubes that were sealed and centrifuged at 10,000 rpm before hematocrit measurement (Hawksley Microhematocrit reader, Hawksley \& Sons, Sussex). A 1.5-ml portion of the blood sample was then centrifuged before duplicate aliquots of plasma were drawn off for glucose and FFA analysis. The remaining whole blood was mixed well before analysis for hemoglobin. Plasma glucose (Sigma Diagnostic), FFA (Wako Chemicals, Germany), and hemoglobin (cyanmethemoglobin method) were assayed within $3 \mathrm{hr}$ of blood draws using a Hitachi U2001 spectrophotometer (Hitachi Instruments Ltd., USA), using standard reagent kits. Blood and plasma volume changes were calculated from hematocrit and hemoglobin using standard equations (Dill \& Costill, 1974).

An additional $4 \mathrm{ml}$ of venous blood was collected into lithium heparin tubes at rest and at 40 and $80 \mathrm{~min}$ of exercise and centrifuged at $5,000 \mathrm{rpm}$ at $4{ }^{\circ} \mathrm{C}$ for $10 \mathrm{~min}$, with plasma extracted into duplicate tubes and frozen at $-60{ }^{\circ} \mathrm{C}$ until analysis. These samples were used for analysis of plasma carnitine fractions by radiometric methods using liquid scintillation as outlined by McGarry and Foster (1985).

Urinary carnitine excretion was determined in each treatment period by means of 24-hr urine collections before the D0 and D14 exercise trials. A 5-ml sample of mixed urine was collected and frozen at $-80{ }^{\circ} \mathrm{C}$ until analysis, and the total volume of urine excreted over the 24-hr period measured to the nearest milliliter. Urinary carnitine fractions were subsequently analyzed (McGarry \& Foster, 1985).

\section{Statistics}

Because of the nature of the study design, comparisons between trials were restricted to D0 versus D14, with treatment (LC vs. P) as the between-subjects effect (i.e., to assess effect of exercise intensity on the whole-body metabolic response to $\mathrm{P}$ and $\mathrm{LC}$ supplementation) and D14 versus D15 (i.e., to assess effect of an acute alteration in substrate availability on whole-body metabolic response to $\mathrm{P}$ and LC supplementation). All data were checked for normality of distribution and homogeneity of variance before analysis. Data were analyzed by two-way repeated-measures analysis of variance with time as a within-subject effect and treatment as a between-subjects effect. Change in values was analyzed by paired-samples $t$ test, or differences between groups with independentsamples $t$ test (SPSS version 15.0, SPSS Inc., Chicago, IL). Significance was accepted at $p<.05$, and where significance was found, Tukey's post hoc test was undertaken to ascertain where it lay. All data are expressed as $M \pm S D$ unless otherwise specified.

\section{Results}

The results that follow are for 15 subjects $(7 \mathrm{P}, 8 \mathrm{LC})$. Unless otherwise specified in the results, differences were not observed between trials that were specific to a particular workload or between the two treatment groups.

The energy content and macronutrient composition of the 2-day preexercise diet for the D0 and D14 trials were $13.3 \pm 1.4 \mathrm{MJ} /$ day, $15 \% \pm 1 \%$ protein, $60 \% \pm 2 \%$ $\mathrm{CHO}$, and $25 \% \pm 1 \%$ fat and for the D15 trial were 13.4 $\pm 0.9 \mathrm{MJ} /$ day, $15 \% \pm 3 \%$ protein, $15 \% \pm 4 \% \mathrm{CHO}$, and $70 \% \pm 4 \%$ fat. For all trials, mean protein intake was 1.6 $\mathrm{g} \cdot \mathrm{kg} \mathrm{BM}^{-1} \cdot \mathrm{day}^{-1}$, whereas $\mathrm{CHO}$ and fat intakes were $6.7 \pm 1.4 \mathrm{~g} \cdot \mathrm{kg} \mathrm{BM}^{-1} \cdot \mathrm{day}^{-1}$ and $86 \pm 11 \mathrm{~g} /$ day for the D0 and D14 trials compared with $1.7 \pm 0.2 \mathrm{~g} / \mathrm{kg} \mathrm{BM}$ and $246 \pm 18 \mathrm{~g}$ for the D15 trial.

Preexercise diet and exercise controls ensured no differences in preexercise body mass between the D0 and D14 trials (P: $72.6 \pm 9.8$ and $73.1 \pm 9.4 \mathrm{~kg}$; LC: $76.6 \pm$ 7.9 and $76.7 \pm 8.1 \mathrm{~kg}$ ) and preexercise plasma glucose concentrations (D0, D14, and D15 P: $5.7 \pm 0.5,5.6 \pm$ $0.5,5.8 \pm 0.5 \mathrm{mmol} / \mathrm{L} ; \mathrm{LC}: 5.8 \pm 0.3,5.4 \pm 0.6,5.6 \pm$ $0.6 \mathrm{mmol} / \mathrm{L}$ ). There was a small yet significant loss of BM between the D14 and D15 trials in both groups (P $0.8 \pm 0.8 \mathrm{~kg}, \mathrm{LC} 0.5 \pm 0.5 \mathrm{~kg} ; p<.05)$ but no difference $(p=.77)$ in preexercise hematocrit between these two trials. There were no differences in median (range) fluid intake (990 [600-1,880] ml, $p=.70$ ) or BM change during the exercise trial $(-100[-850$ to 450$] \mathrm{g}, p=.71)$ between trials in either group or between groups. Blood and plasma volume fell with each increase in workload, but there were no differences between trials within or between the two groups, so no correction of blood variables was undertaken. The lack of difference between trials for blood volume, plasma volume, NBM change, and fluid intake indicates there was a similar change in hydration status throughout exercise in all trials, with no difference between the two treatment groups.

Mean exercise HR (Figure 1) and rating of perceived exertion ( $8 \pm 1$ and $17 \pm 1$ for $20 \%$ and $80 \%$ workloads in both $\mathrm{P}$ and LC groups) increased with each power output in all trials $(p<.05)$. HR was higher (Figure 1$)$ in the $\mathrm{P}$ than LC at the $20 \%$ workload at D14 and was higher in P than LC at the $20 \%, 40 \%$, and $60 \%$ workloads on D15 ( $p$ $<.05$ ), with no difference between groups at any workload during the D0 trial. Rating of perceived exertion did not differ between trials in either group. 

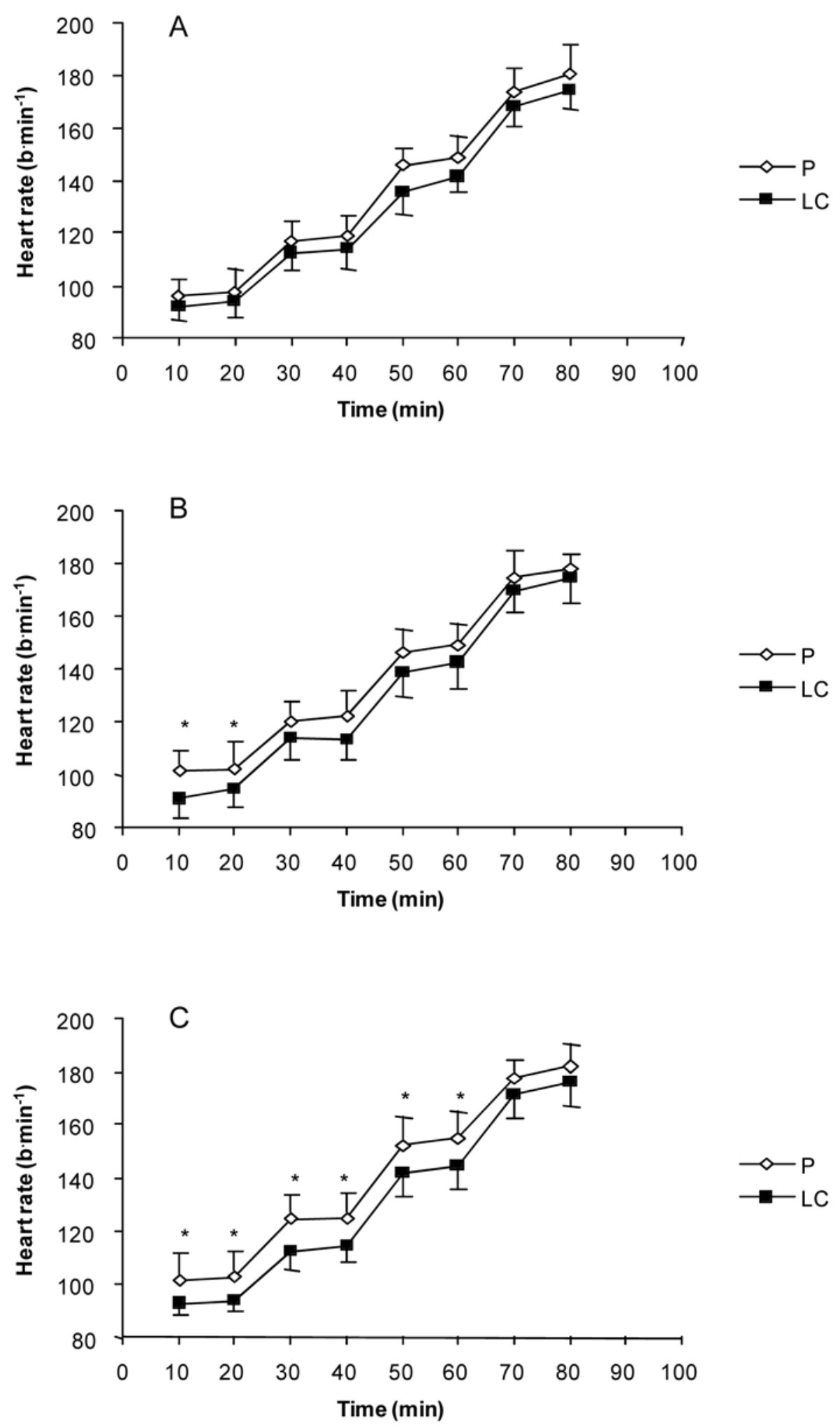

Figure 1 - Heart-rate response during graded exercise on (A) Day 0, (B) Day 14, and (C) Day 15, $M \pm S D$. *Significant difference between L-carnitine (LC) and placebo (P) trials, $p<.05$. 


\section{Carnitine Fractions}

All carnitine fractions were within the reported normal ranges, and there was no difference between groups at D0 (Table 3). Supplementation increased resting plasma total (TC) and free (FC) carnitine fractions in the LC group ( $p<.01$ at both D14 and D15 compared with D0), with no change in the $\mathrm{P}$ group. Urinary carnitine excretion was elevated after D14 supplementation for all carnitine fractions (LC group: D0 TC $263 \pm 58$, FC $98 \pm 52$, acyl-carnitine [AC] $166 \pm 49 ;$ D14 TC $1,345 \pm$ 328 , FC $860 \pm 286$, AC $485 \pm 247 \mu \mathrm{mol} /$ day, $p<.01)$, with no change in the P group (D0 TC $293 \pm 93$, FC 140 $\pm 108, \mathrm{AC} 153 \pm 57$; D14 TC $309 \pm 112$, FC $125 \pm 82$, AC $183 \pm 38 \mu \mathrm{mol} / \mathrm{da}$.

Compared with resting values, plasma TC increased ( $p<.05$ for LC group, n.s. for P group) and FC fell ( $p<$ .05 , except for LC D0 trial) at the $80 \%$ workload for both D0 and D14 trials in both groups. Plasma AC increased at the $80 \%$ workload compared with both rest and the $40 \%$ workload in all trials $(p<.05)$ except for the D0 trial in P. As a result, the AC:FC ratio was higher at the $80 \%$ workload than at rest or the $40 \%$ workload in all trials for both groups (Figure $2 ; p<.05$ ). The high fat intake increased plasma TC and AC during exercise compared with D14, but this reached significance only in the LC group $(p<.05)$. The high fat intake also prevented a fall in free carnitine at $80 \% \mathrm{VO}_{2 \text { peak }}$ and appears to have induced a greater change in TC and AC responses to exercise, particularly in the LC group, where plasma TC and AC increased progressively as workload increased $(p<.05$, Table 3$)$.

\section{Metabolic Responses}

The high fat intake resulted in higher plasma FFA concentrations at rest and during exercise $(p<.01$; Table 4$)$, a higher blood glycerol concentration during exercise at all workloads $(p<.01$; Table 4$)$, and a lower blood lactate at the $80 \%$ workload compared with the D0 or D14 trial in both groups, with no differences in these variables observed between D0 and D14. There was no difference between D0 and D14, between D14 and $\mathrm{D} 15$, or between groups for bicarbonate, $\mathrm{pH}$, and $\mathrm{pCO}_{2}$. There was a significant effect of time for plasma glucose, lactate, bicarbonate, $\mathrm{pH}$, and $\mathrm{pCO}_{2}(p<.05)$, with the $80 \%$ workload being different from rest. Although blood lactate concentration (Table 4) was somewhat lower at the $80 \%$ workload after 2 weeks of LC supplementation than at D0, this did not reach statistical significance (mean difference $0.8 \mathrm{mM}, 95 \%$ CI 0.3 to $-1.8, p=.12$ ). Plasma glucose was not different between LC and P groups on the D0 or D14 trials but was lower during exercise in the LC group on the D15 trial $(p<.05$ for $40 \%$ and $60 \%$ intensities; Figure 3).

\section{Substrate Utilization}

$\mathrm{VO}_{2}$, carbon dioxide exhalation $\left(\mathrm{VCO}_{2}\right)$, and minute ventilation $(\mathrm{VE})$ all increased with each power output increment $(p<.01)$ and did not differ between treatment groups or between D0 and D14 trials. $\mathrm{VO}_{2}$ was higher on the D15 trial than at D0 and D14 at each workload ( $p$ $<.01$ ), whereas $\mathrm{VCO}_{2}$ did not differ between trials. VE was higher on the D15 trial than at D0 and D14 at the $80 \%$ workload in both treatment groups, with no difference between trials at the other workloads. Respiratoryexchange ratio (RER) was not different between D0 and D14 in either group but was lower during the D15 trial than on both D0 and D14 in both P and LC $(p<.01)$. At D0 and D14, RER was stable from the $20 \%$ to $60 \%$ workloads, then rose during the $80 \%$ workload $(p<.01)$, but during the D15 trial the increase in RER began at the $60 \%$ workload $(p<.05)$.

There was no difference in the estimated rate of whole-body $\mathrm{CHO}$ or fat oxidation between treatment groups at either D0 or D14 (Figures 4 and 5). The 24-hr

Table 3 Plasma Carnitine Fractions ( $\mu \mathrm{mol} / \mathrm{L}$ ) at Rest and After Exercise at $40 \%$ and $80 \%$ of Workload at $\mathrm{VO}_{2 \text { peak }}, M \pm S D$

\begin{tabular}{|c|c|c|c|c|c|c|c|}
\hline \multirow[b]{2}{*}{ Fraction } & \multirow[b]{2}{*}{ Trial } & \multicolumn{3}{|c|}{ Placebo } & \multicolumn{3}{|c|}{ L-Carnitine } \\
\hline & & Rest & $40 \%$ workload & $80 \%$ workload & Rest & $40 \%$ workload & $80 \%$ workload \\
\hline \multirow[t]{3}{*}{ Total } & Day 0 & $49 \pm 9$ & $47 \pm 7$ & $55 \pm 10$ & $44 \pm 10$ & $45 \pm 9$ & $53 \pm 8^{b}$ \\
\hline & Day 14 & $46 \pm 6$ & $47 \pm 7$ & $55 \pm 8$ & $62 \pm 9^{a}$ & $66 \pm 13^{a}$ & $74 \pm 14^{\mathrm{a}, \mathrm{b}}$ \\
\hline & Day 15 & $53 \pm 7$ & $56 \pm 4$ & $65 \pm 6^{b}$ & $64 \pm 14^{\mathrm{a}}$ & $78 \pm 17^{\mathrm{a}, \mathrm{b}}$ & $95 \pm 22^{\mathrm{a}, \mathrm{b}, \mathrm{c}}$ \\
\hline \multirow[t]{3}{*}{ Free } & Day 0 & $38 \pm 8$ & $37 \pm 6$ & $34 \pm 5^{b, c}$ & $35 \pm 6$ & $35 \pm 4$ & $31 \pm 2$ \\
\hline & Day 14 & $37 \pm 4$ & $37 \pm 3$ & $33 \pm 4^{b, c}$ & $48 \pm 4^{\mathrm{a}}$ & $49 \pm 4^{\mathrm{a}}$ & $44 \pm 5^{\mathrm{a}, \mathrm{b}, \mathrm{c}}$ \\
\hline & Day 15 & $38 \pm 5$ & $39 \pm 3$ & $38 \pm 3^{\mathrm{d}}$ & $45 \pm 7^{\mathrm{a}}$ & $47 \pm 6^{\mathrm{a}}$ & $47 \pm 5^{\mathrm{a}}$ \\
\hline \multirow[t]{3}{*}{ Acyl } & Day 0 & $11 \pm 2$ & $10 \pm 4$ & $22 \pm 6$ & $9 \pm 8$ & $10 \pm 8$ & $22 \pm 8^{b}$ \\
\hline & Day 14 & $9 \pm 4$ & $10 \pm 5$ & $23 \pm 4^{b}$ & $14 \pm 9$ & $18 \pm 12$ & $30 \pm 12^{b}$ \\
\hline & Day 15 & $14 \pm 4$ & $16 \pm 5$ & $27 \pm 4^{b}$ & $20 \pm 15$ & $31 \pm 16^{\mathrm{b}, \mathrm{d}}$ & $48 \pm 18^{\mathrm{b}, \mathrm{d}}$ \\
\hline
\end{tabular}

${ }^{\mathrm{a} S i g n i f i c a n t l y ~ g r e a t e r ~ t h a n ~ L-c a r n i t i n e, ~ D a y ~} 0$, and placebo for the same trial, $p<.05$. ${ }^{\mathrm{b}}$ Significantly different from resting value, $p<.05$. ${ }^{\mathrm{c}}$ Significantly different from $40 \%$ workload, $p<.05$. dSignificantly different from the same workload in the other trials for the same group, $p<.05$. 
A

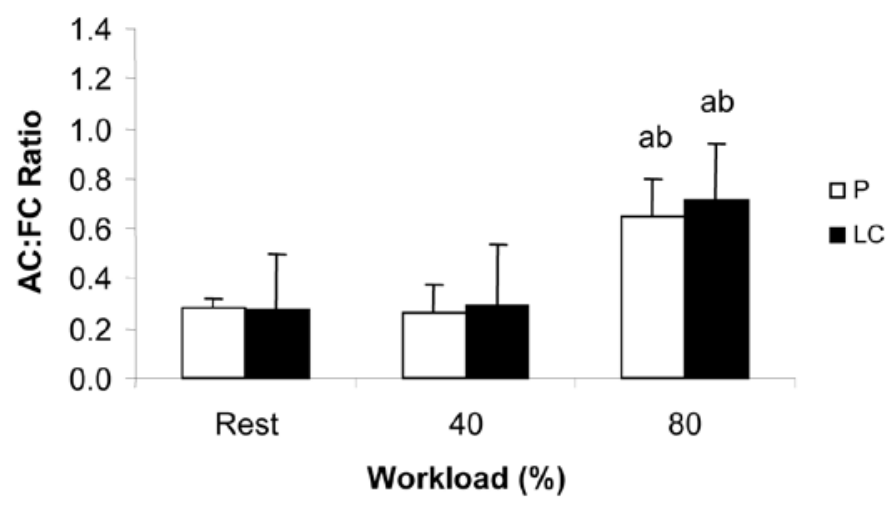

B

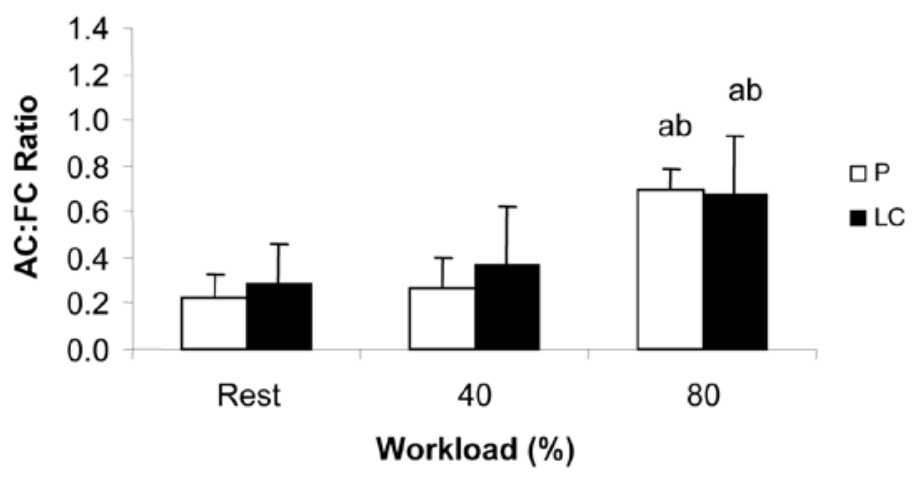

C

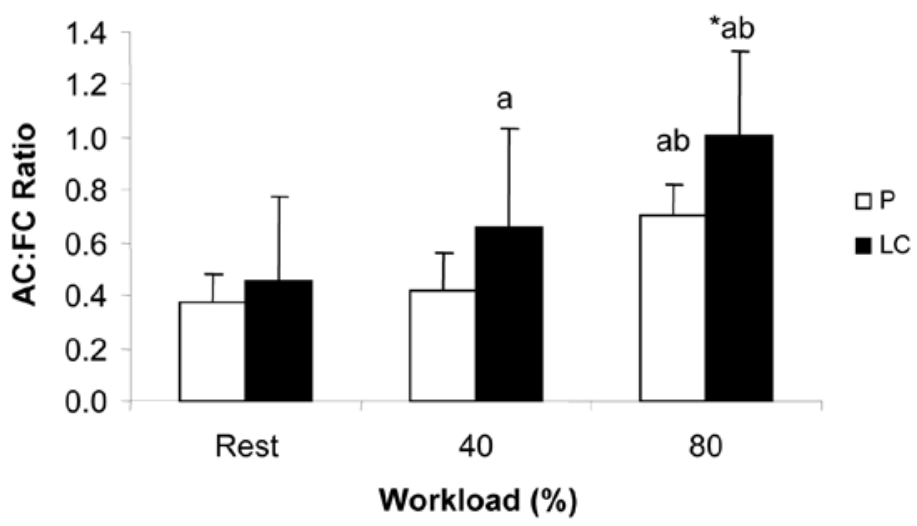

Figure 2 - Plasma acyl-carnitine-to-free-carnitine ratio on (A) Day 0, (B) Day 14, and (C) Day 15, $M \pm S D$. P = placebo; LC =

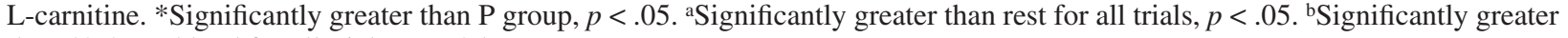
than $40 \%$ workload for all trials, $p<.05$.

high fat intake changed the contribution of $\mathrm{CHO}$ and fat to metabolism in both the $\mathrm{P}$ and LC groups compared with D14, particularly in the first three workloads ( $p$ $<.05$; Figures 4 and 5). The rate of fat oxidation was lowest at the $20 \%$ workloads, with peak rates of oxidation at the $60 \%$ workload $(p<.01$ compared with $20 \%)$, with no further change from the $60 \%$ to $80 \%$ workload in all trials. In the D15 trials there was also a significant difference between the $20 \%$ and $40 \%$ workloads $(p<$ .05 ) that was not present at either the D0 or D14 trial. Total estimated whole-body fat oxidation over $60 \mathrm{~min}$ of exercise was not different between LC and P on the D0 trial and was not different between LC and P on the D14 trial (P $21 \pm 7 \mathrm{~g}, \mathrm{LC} 29 \pm 10 \mathrm{~g}$ ). Total fat oxidation over 60 min of exercise increased $(p<.01)$ from D14 to D15 trials in both LC and P groups. 
Table 4 Plasma Free Fatty Acids, Blood Glycerol, and Blood Lactate ( $\mathrm{mmol} / \mathrm{L})$ for Placebo and L-Carnitine Groups, $M \pm S D$

\begin{tabular}{|c|c|c|c|c|c|c|c|}
\hline \multirow[b]{2}{*}{ Variable } & \multirow[b]{2}{*}{ Group } & \multirow[b]{2}{*}{ Trial } & \multirow[b]{2}{*}{ Rest } & \multicolumn{4}{|c|}{ Workload } \\
\hline & & & & $20 \%$ & $40 \%$ & $60 \%$ & $80 \%$ \\
\hline \multirow[t]{6}{*}{ Free fatty acids } & Placebo & Day 0 & $0.23 \pm 0.20$ & $0.21 \pm 0.17$ & $0.28 \pm 0.19$ & $0.28 \pm 0.14$ & $0.21 \pm 0.05$ \\
\hline & & Day 14 & $0.20 \pm 0.21$ & $0.21 \pm 0.17$ & $0.28 \pm 0.18$ & $0.27 \pm 0.15$ & $0.19 \pm 0.04$ \\
\hline & & Day 15 & $0.48 \pm 0.12^{\mathrm{a}}$ & $0.39 \pm 0.10^{\mathrm{a}}$ & $0.52 \pm 0.17^{a}$ & $0.49 \pm 0.13^{a}$ & $0.43 \pm 0.28^{a}$ \\
\hline & L-carnitine & Day 0 & $0.36 \pm 0.23$ & $0.33 \pm 0.25$ & $0.42 \pm 0.36$ & $0.41 \pm 0.33$ & $0.29 \pm 0.20$ \\
\hline & & Day 14 & $0.35 \pm 0.20$ & $0.37 \pm 0.19$ & $0.55 \pm 0.26$ & $0.51 \pm 0.22$ & $0.36 \pm 0.16$ \\
\hline & & Day 15 & $0.57 \pm 0.30^{\mathrm{a}}$ & $0.49 \pm 0.22^{\mathrm{a}}$ & $0.68 \pm 0.32^{\mathrm{a}}$ & $0.74 \pm 0.37^{\mathrm{a}}$ & $0.65 \pm 0.33^{\mathrm{a}}$ \\
\hline \multirow[t]{6}{*}{ Glycerol } & Placebo & Day 0 & $0.06 \pm 0.04$ & $0.07 \pm 0.04$ & $0.13 \pm 0.06$ & $0.14 \pm 0.06$ & $0.20 \pm 0.07$ \\
\hline & & Day 14 & $0.05 \pm 0.03$ & $0.06 \pm 0.02$ & $0.10 \pm 0.03$ & $0.12 \pm 0.04$ & $0.18 \pm 0.05$ \\
\hline & & Day 15 & $0.06 \pm 0.03$ & $0.15 \pm 0.06^{\mathrm{b}, \mathrm{c}}$ & $0.20 \pm 0.06^{b}$ & $0.31 \pm 0.08^{b}$ & $0.37 \pm 0.06^{\mathrm{b}}$ \\
\hline & L-carnitine & Day 0 & $0.08 \pm 0.04$ & $0.09 \pm 0.05$ & $0.14 \pm 0.07$ & $0.17 \pm 0.09$ & $0.23 \pm 0.11$ \\
\hline & & Day 14 & $0.07 \pm 0.03$ & $0.10 \pm 0.04$ & $0.16 \pm 0.06$ & $0.22 \pm 0.08$ & $0.27 \pm 0.08$ \\
\hline & & Day 15 & $0.10 \pm 0.08$ & $0.15 \pm 0.09^{b, c}$ & $0.25 \pm 0.08^{b}$ & $0.33 \pm 0.11^{b}$ & $0.45 \pm 0.12^{b}$ \\
\hline \multirow[t]{6}{*}{ Lactate } & Placebo & Day 0 & $0.87 \pm 0.37$ & $0.82 \pm 0.41$ & $0.95 \pm 0.33$ & $1.51 \pm 0.47$ & $5.99 \pm 0.94$ \\
\hline & & Day 14 & $0.90 \pm 0.32$ & $0.78 \pm 0.26$ & $0.93 \pm 0.35$ & $1.45 \pm 0.51$ & $5.84 \pm 1.40$ \\
\hline & & Day 15 & $0.68 \pm 0.45$ & $0.67 \pm 0.34$ & $0.77 \pm 0.37$ & $1.31 \pm 0.47$ & $5.33 \pm 0.91^{\mathrm{d}}$ \\
\hline & L-carnitine & Day 0 & $0.74 \pm 0.14$ & $0.67 \pm 0.20$ & $0.87 \pm 0.34$ & $1.36 \pm 0.32$ & $6.05 \pm 1.40$ \\
\hline & & Day 14 & $0.64 \pm 0.14$ & $0.66 \pm 0.20$ & $0.77 \pm 0.27$ & $1.31 \pm 0.46$ & $5.29 \pm 1.89$ \\
\hline & & Day 15 & $0.62 \pm 0.16$ & $0.53 \pm 0.14$ & $0.69 \pm 0.28$ & $0.99 \pm 0.23$ & $4.99 \pm 1.66^{\mathrm{d}}$ \\
\hline
\end{tabular}

${ }^{a}$ Significantly greater than Day $0 .{ }^{b}$ Significantly greater than Day 0 and Day 14 . ${ }^{c}$ Lower than $60 \%$ and $80 \%$ workloads for all trials, $p<.05$. ${ }^{\mathrm{d}}$ Significantly lower than Day 0.

\section{Discussion}

In the current study there was a lower HR in the LC group during exercise at $20 \%$ of $\mathrm{VO}_{2 \text { peak }}$ in the D14 trial and at $20 \%, 40 \%$, and $60 \%$ of $\mathrm{VO}_{2 \text { peak }}$ in the $\mathrm{D} 15$ trial than with $\mathrm{P}$ but no difference between groups during the D0 trial, a greater alteration in plasma $\mathrm{AC}: \mathrm{FC}$ ratio under conditions of high fat availability in the LC group than with placebo, a lower plasma glucose in the LC group during exercise on the D15 trial than with P but not during the D0 and D14 trials under conditions of high $\mathrm{CHO}$ availability, and no significant difference in the whole-body estimated rates of $\mathrm{CHO}$ and fat oxidation at any exercise intensity after LC supplementation compared with $\mathrm{P}$.

The observed difference in HR response to the low intensities of exercise $(20 \%, 40 \%$, and $60 \%$ of peak power) between the LC and $\mathrm{P}$ groups in the D15 trial may reflect an effect of carnitine on cardiac-muscle contractility. Gurlek et al. (2000) observed a greater increase in left-ventricular ejection fraction after 4 weeks of LC supplementation in patients with ischemic cardiomyopathy. Bartels et al. (1992) observed an increase in cardiac output after intravenous administration of LC in normotensive coronary artery disease patients. Greig, Jones, Cooper, Sargeant, and Forte (1987) observed a lower HR during exercise at $50 \%$ of $\mathrm{VO}_{2 \text { peak }}$ after 2 weeks of oral LC supplementation in normal active humans, and Natali et al. (1993) reported a lower HR after LC infusion. The current study is consistent with these previous observations and lends support to a possible positive inotropic effect and negative chronotropic effect of elevated plasma carnitine on cardiac muscle in the presence of high fat availability. The mechanism underlying this effect requires more detailed cardiovascular function investigation.

van Loon et al. (2001) demonstrated a decline in muscle FC on going from rest to exercise at intensities of $>40 \%$ of maximal workload $\left(\mathrm{W}_{\max }\right)$ and suggested that this reduction in FC availability may be a primary driving factor in reducing fat oxidation during exercise at higher intensities $\left(75 \% \mathrm{~W}_{\max }\right)$. Thus, for LC supplementation to have an effect on skeletal-muscle substrate utilization during exercise it would seem that an increase in the FC pool of that tissue must be established, and the intensity would need to be sufficiently high to alter FC availability. Therefore, the lack of any difference between trials in the metabolic response to exercise at baseline (D0) and after 2 weeks of supplementation in the current study strongly suggests that there were no differences in the $\mathrm{FC}$ availability or $\mathrm{AC}$ : $\mathrm{FC}$ ratio in any tissues that were contributing to the whole-body metabolic response to exercise. This suggestion is supported by the similar changes in plasma carnitine fractions and $\mathrm{AC}: \mathrm{FC}$ ratio in the current study at 

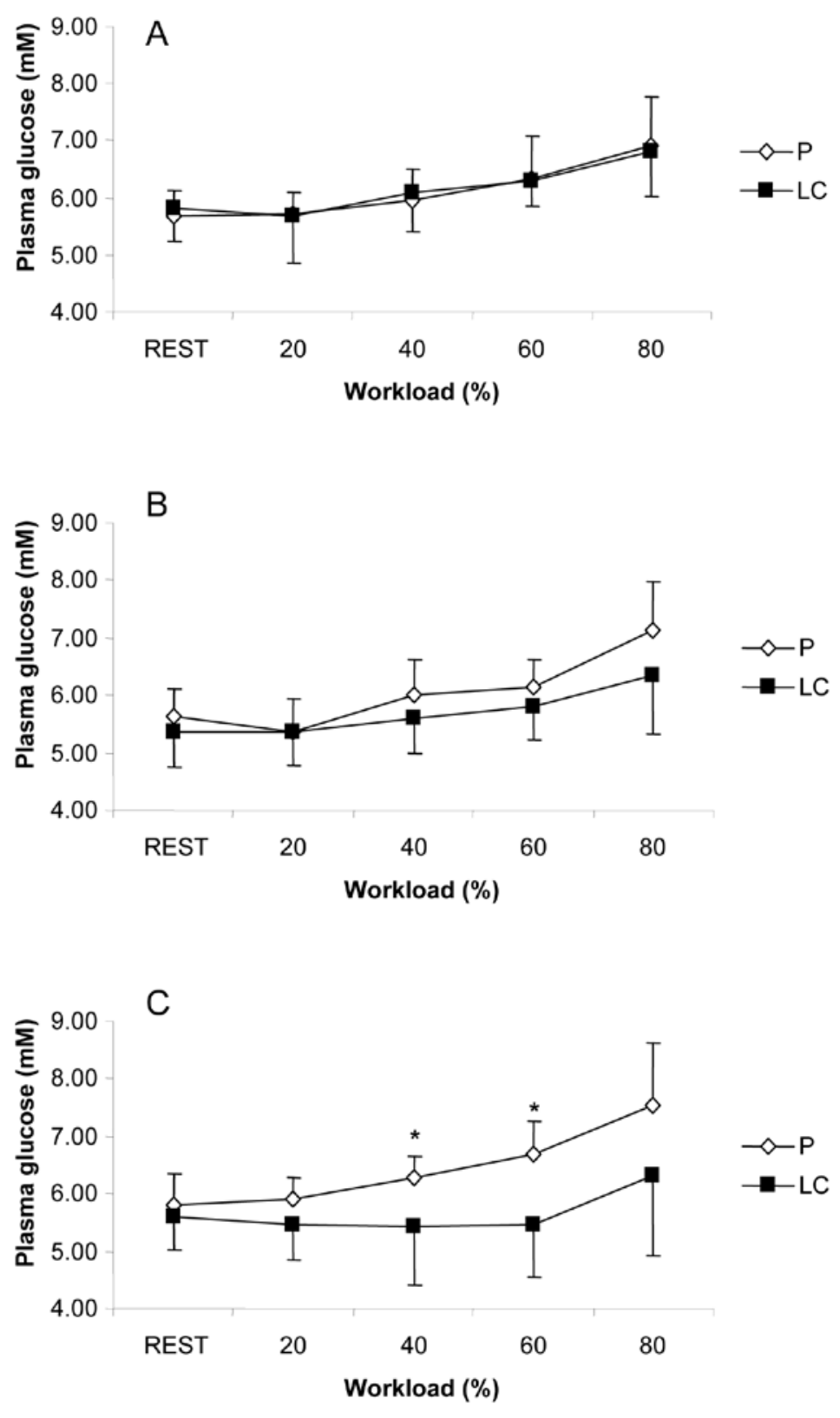

Figure 3 - Plasma glucose response during graded exercise on (A) Day 0, (B) Day 14, and (C) Day 15, $M \pm S D . \mathrm{P}=$ placebo; LC $=$ L-carnitine. *Significant difference between LC and P, $p<.05$.

baseline and after 2 weeks LC supplementation across the exercise intensities studied. It should be noted that the change in plasma $\mathrm{AC}: \mathrm{FC}$ ratio is thought to reflect changes in skeletal-muscle $\mathrm{AC}$ : $\mathrm{FC}$ ratio during exercise (Friolet, Hoppeler, \& Krahenbuhl, 1994). The higher AC:FC ratio in the LC group than with $\mathrm{P}$ during the highest intensity of exercise on the D15 trial could reflect greater acetyl-group buffering by FC in metabolically active tissues (Friolet et al., 1994), which is likely a result of increased acetyl-CoA formation through pyruvate dehydrogenase, thus indicating a higher rate of glycolysis in the LC group (Stephens, Constantin-
Teodosiu, \& Greenhaff, 2007). This is consistent with the observations of Wall et al. (2010), who found increased pyruvate dehydrogenase activity in higher intensity exercise after oral carnitine supplementation. However, the changes noted in the current study did not result in any whole-body substrate-utilization differences assessed using indirect calorimetry at this intensity. The lack of effect on measured substrate utilization may also be influenced by the relatively short exercise duration at each workload (20 min); indeed, this may explain why we have not been able to replicate our previous observation of higher total $\mathrm{CHO}$ 

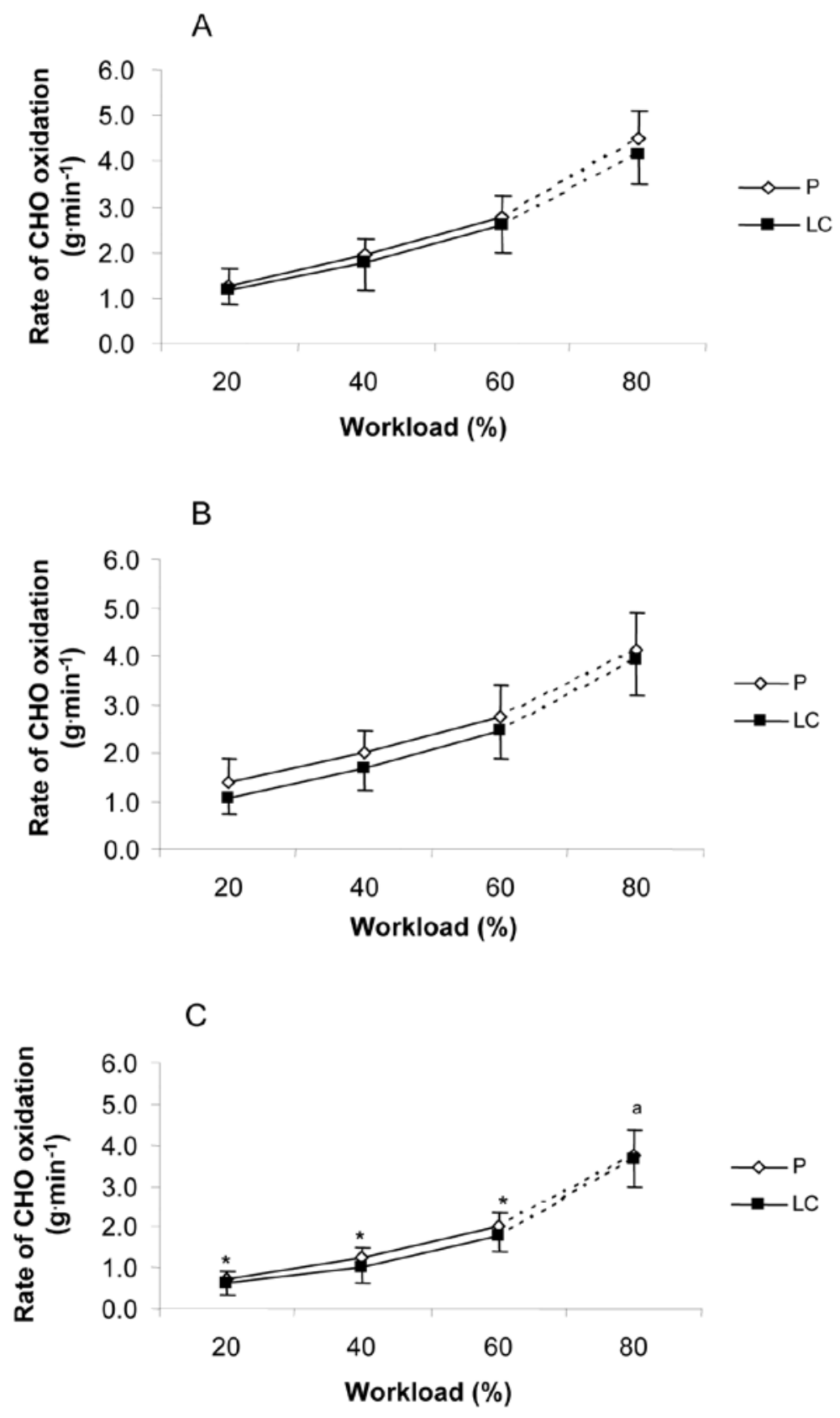

Figure 4 - Estimated rate of whole-body carbohydrate (CHO) oxidation during exercise on (A) Day 0, (B) Day 14, and (C) Day $15, M \pm S D . \mathrm{P}=$ placebo; $\mathrm{LC}=\mathrm{L}$-carnitine. *Rate of $\mathrm{CHO}$ oxidation significantly lower in $\mathrm{D} 15$ than D14 in both $\mathrm{P}$ and LC, $p<.01$.

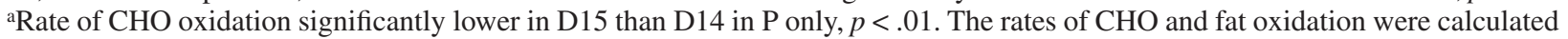
at $80 \mathrm{~min}$ and are shown as dashed lines to present a more complete comparison between trials, despite the fact that ventilatory parameters at $80 \% \mathrm{VO}_{2 \text { peak }}$ did not achieve steady state, being affected by changes in the bicarbonate pool (blood lactate $>4 \mathrm{mmol} / \mathrm{L}$, $\mathrm{pCO}_{2}$ and bicarbonate levels decreasing).

oxidation over 60 min of exercise after 2 weeks of LC supplementation than with P (Abramowicz \& Galloway, 2005). A carnitine-induced increase in glucose oxidation by cardiac muscle, as reported using an in vitro model by Rodgers et al. (2001), would likely not be large enough to be detectable using whole-body indirect calorimetry measurements. The increased glucose oxidation of $0.5 \mu \mathrm{mol}$. $\mathrm{g}^{-1} \cdot \min ^{-1}$ in the presence of carnitine noted by Rodgers et al. (2001) would amount to only a $0.03-\mathrm{g} / \mathrm{min}$ change in glucose oxidation for an average human heart mass of $300 \mathrm{~g}$. However, any change in cardiac-muscle substrate oxidation could be an important avenue to explore in an attempt to explain the observed differences in HR noted between trials in the current study. 


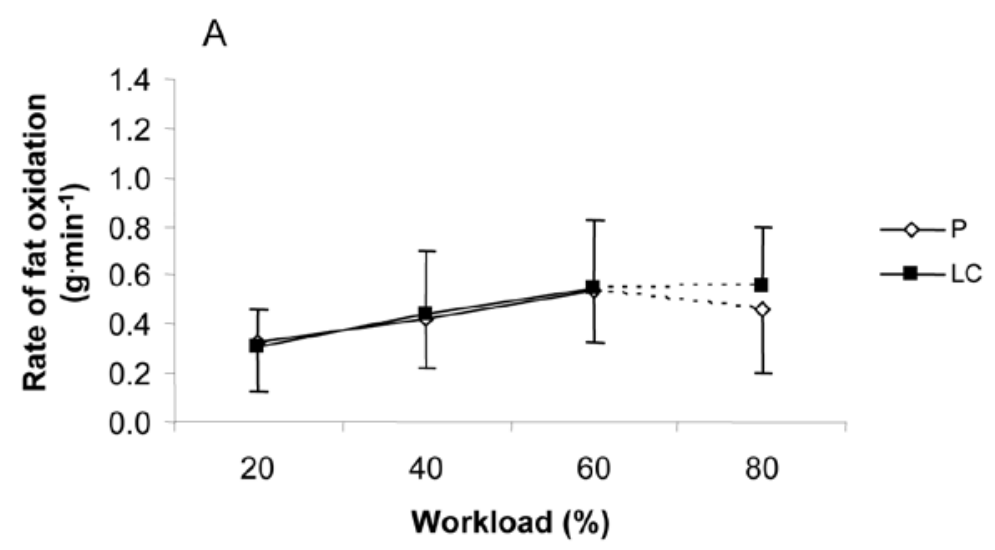

B

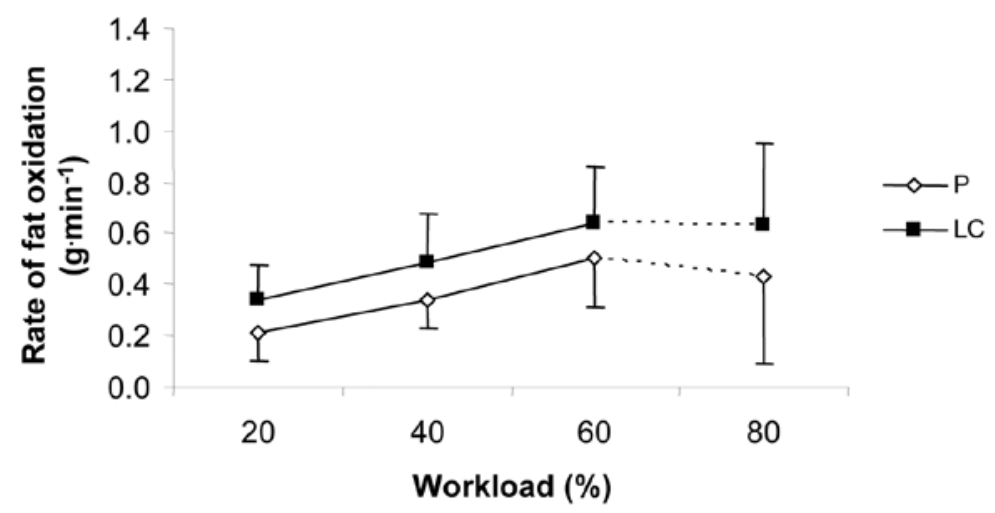

C

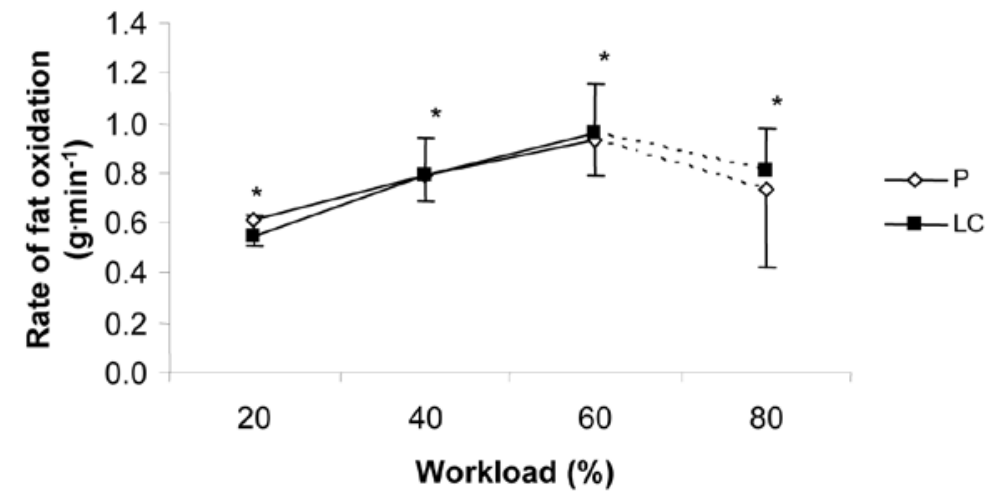

Figure 5 - Estimated whole-body rate of fat oxidation during exercise on (A) Day 0, (B) Day 14, and (C) Day 15, $M \pm S D . \mathrm{P}=$ placebo; LC = L-carnitine. *Significantly higher on D15 than D0 and D14 in both P and LC, $p<.01$.

The difference in plasma glucose concentration observed during the D15 trial combined with elevated plasma TC, FC, and AC could also be explained by an increased nonoxidative glucose disposal effect of LC rather than any change in glucose oxidation. Previous studies have shown that an elevation of plasma carnitine concentration increases nonoxidative glucose disposal during hyperinsulinemic euglycemic clamps in controls and in patients with Type 2 diabetes (Giancaterini et al., 2000; Mingrone et al., 1999) and increases glucose disposal during intravenous glucose-tolerance testing (De Gaetano, Mingrone, Castagneto, \& Calvani, 1999), and we have recently shown this to occur after oral LC supplementation in lean active males (Galloway, Craig, \& Cleland, 2011). Furthermore, Stephens et al. (2006) have observed increased glycogen storage in skeletal muscle after carnitine infusions. This potential effect of carnitine on glucose disposal could be important in longer 
duration exercise or in recovery of glycogen stores after prolonged exercise.

\section{Conclusion}

The results of this study indicate that 2 weeks supplementation of $3 \mathrm{~g}$ LC per day with high $\mathrm{CHO}$ availability does not result in a significant change in whole-body substrate metabolism during 20-min bouts of exercise over a range of intensities (20-80\% of $\mathrm{VO}_{2 \text { peak }}$ ). However, under conditions of high fat availability, there is evidence of an effect of LC supplementation, with a decline in blood glucose in the LC group compared with $\mathrm{P}$ and a reduction in the HR response to exercise. These alterations may reflect carnitine-induced changes in glucose disposal and oxidation in a range of metabolically active tissues, but any changes in oxidation may be too small to be detected at the whole-body level. Future work may wish to focus on the potential beneficial effects of carnitine on cardiovascular responses to exercise, as well as on substrate availability over more prolonged exercise periods or on glycogen restoration in recovery from exercise, to further understand the specific roles of this dietary component.

\section{Acknowledgments}

The authors would like to thank Lonza Ltd., Basel, for their support of this research.

\section{References}

Abramowicz, W.N., \& Galloway, S.D.R. (2005). Effects of acute versus chronic administration of L-carnitine L-tartrate on the metabolic responses to submaximal exercise in males and females. International Journal of Sport Nutrition and Exercise Metabolism, 15, 386-400.

Bartels, G.L., Remme, W.J., Pillay, M., Schonfeld, D.H., Cox, P.H., Kruijssen, H.A., \& Knufman, N.M. (1992). Acute improvement of cardiac function with intravenous L-propionylcarnitine in humans. Journal of Cardiovascular Pharmacology, 20, 157-164.

Boobis, L.H., \& Maughan, R.J. (1983). A simple one-step enzymatic fluorometric method for the determination of glycerol in $20 \mu \mathrm{l}$ of plasma. Clinica Chimica Acta, 132, 173-179.

Borg, G.A.V. (1982). Psychophysical bases of perceived exertion. Medicine and Science in Sports and Exercise, 14, 377-381.

Brass, E.P., \& Hiatt, W.R. (1998). The role of carnitine and carnitine supplementation during exercise in man and in individuals with special needs. Journal of the American College of Nutrition, 17, 207-215.

Broad, E.M., Maughan, R.J., \& Galloway, S.D.R. (2008). Carbohydrate, protein and fat metabolism during exercise following oral carnitine supplementation in man. International Journal of Sport Nutrition and Exercise Metabolism, 18, 567-584.

Broderick, T.L., Panagakis, G., DiDomenico, D., Gamble, J., Lopaschuk, G.D., Shug, A.L., \& Paulson, D.J. (1995).
L-carnitine improvement of cardiac function is associated with a stimulation in glucose but not fatty acid metabolism in carnitine-deficient hearts. Cardiovascular Research, $30,815-820$.

Burke, L.M. (1996). The complete guide to food for sports performance. Sydney, Australia: Allen \& Unwin.

Decombaz, J., Deriaz, O., Acheson, K., Gmuender, B., \& Jequier, E. (1993). Effect of L-carnitine on submaximal exercise metabolism after depletion of muscle glycogen. Medicine and Science in Sports and Exercise, 25, 733-749.

De Gaetano, A., Mingrone, G., Castagneto, M., \& Calvani, M. (1999). Carnitine increases glucose disposal in humans. Journal of the American College of Nutrition, 18, 289-295.

Dill, D.B., \& Costill, D.L. (1974). Calculation of percentages changes in volumes of blood, plasma, and red cells in dehydration. Journal of Applied Physiology, 37, 247-248.

Ferrannini, E., Buzzigoli, G., Bevilacqua, S., Boni, C., Del Chiaro, D., Oleggini, M., . . Maccari, F. (1988). Interaction of carnitine with insulin-stimulated glucose metabolism in humans. The American Journal of Physiology, 255, E946-E952.

Friolet, R., Hoppeler, H., \& Krahenbuhl, S. (1994). Relationship between the coenzyme A and the carnitine pools in human skeletal muscle at rest and after exhaustive exercise under normoxic and acutely hypoxic conditions. The Journal of Clinical Investigation, 94, 1490-1495.

Fritz, I.B. (1963). Carnitine and its role in fatty acid metabolism. Advances in Lipid Research, 1, 285-334.

Galloway, S.D.R., \& Broad, E.M. (2005). Oral L-carnitine supplementation and exercise metabolism. Chemical Monthly, 136, 1391-1410.

Galloway, S.D.R., Craig, T.P., \& Cleland, S.J. (2011). Effects of oral L-carnitine supplementation on insulin sensitivity indices in response to glucose feeding in lean and overweight/obese males. Amino Acids, 41(2), 507-515.

Giancaterini, A., De Gaetano, A., Mingrone, G., Gniuli, D., Liverani, E., Capristo, E., \& Greco, A.V. (2000). AcetylL-carnitine infusion increases glucose disposal in Type 2 diabetic patients. Metabolism: Clinical and Experimental, 49, 704-708.

Greig, C.F.K.M., Jones, D.A., Cooper, M., Sargeant, A.J., \& Forte, C.A. (1987). The effect of oral supplementation with L-carnitine on maximum and submaximum exercise capacity. European Journal of Applied Physiology, 56, 457-460.

Gurlek, A., Tutar, E., Akcil, E., Dincer, I., Erol, C., Kocaturk, P.A., \& Oral, D. (2000). The effects of L-carnitine treatment on left ventricular function and erythrocyte superoxide dismutase activity in patients with ischemic cardiomyopathy. European Journal of Heart Failure, 2, 189-193.

Harper, P., Wadstrom, C., Backman, L., \& Cederblad, G. (1995). Increased liver carnitine content in obese women. The American Journal of Clinical Nutrition, 61, 18-25.

Hino, K., Nishikawa, M., Sato, E., \& Inoue, M. (2005). L-carnitine inhibits hypoglycemia-induced brain damage in the rat. Brain Research, 1053, 77-87. 
Kai, S., Yakushiji, K., Yamauchi, M., Ito, C., Kuwajima, M., Osada, Y., \& Toshimori, K. (2005). Expression of novel organic cation/carnitine transporter (OCTN2) in the mouse pancreas. Tissue \& Cell, 37, 309-315.

Karlic, H., \& Lohninger, A. (2004). Supplementation of L-carnitine in athletes: Does it make sense? Nutrition (Burbank, Los Angeles County, Calif.), 20, 709-715.

Lopaschuk, G. (2000). Regulation of carbohydrate metabolism in ischemia and reperfusion. American Heart Journal, 139, S115-S119.

Maughan, R.J. (1982). A simple, rapid method for the determination of glucose, lactate, pyruvate, alanine, 3-hydroxybutyrate and acetoacetate on a single $20-\mu$ l blood sample. Clinica Chimica Acta, 122, 231-240.

McGarry, J.D., \& Foster, D.W. (1985). Free and esterified carnitine-Radiometric method. In H.U. Bergmeyer (Ed.), Methods of enzymatic analysis (pp. 474-481). Berlin: $\mathrm{VCH}$ Verlagsgesellschaft mbH.

Mingrone, G., Greco, A.V., Capristo, E., Benedetti, G., Giancaterini, A., De Gaetano, A., \& Gasbarrini, G. (1999). L-carnitine improves glucose disposal in Type 2 diabetic patients. Journal of the American College of Nutrition, $18,77-82$.

Natali, A., Santoro, D., Brandi, L.S., Faraggiana, D., Ciociaro, D., Pecori, N., . . Ferrannini, E. (1993). Effects of acute hypercarnitinemia during increased fatty substrate oxidation in man. Metabolism: Clinical and Experimental, 42, 594-600.

Norton, K., \& Olds, T. (2000). Anthropometrica. Sydney, Australia: University of New South Wales Press.

Peronnet, F., \& Massicotte, D. (1991). Table of nonprotein respiratory quotient: An update. Canadian Journal of Sport Sciences, 16, 23-29.

Rodgers, R.L., Christe, M.E., Tremblay, G.C., Babson, J.R., \& Daniels, T. (2001). Insulin-like effects of a physiologic concentration of carnitine on cardiac metabolism. Molecular and Cellular Biochemistry, 226, 97-105.

Roepstorff, C., Halberg, N., Hillig, T., Saha, A.K., Ruderman, N.B., Wojtaszewski, J.F.P., ... Kiens, B. (2005). Malonyl$\mathrm{CoA}$ and carnitine in regulation of fat oxidation in human skeletal muscle during exercise. The American Journal of Physiology, 288, E133-E142.

Romijn, J.A., Coyle, E.F., Sidossis, L.S., Gastaldelli, A., Horowitz, J.F., Endert, E., \& Wolfe, R.R. (1993). Regulation of endogenous fat and carbohydrate metabolism in relation to exercise intensity and duration. The American Journal of Physiology, 265, E380-E391.

Stephens, F.B., Constantin-Teodosiu, D., \& Greenhaff, P.L. (2007). New insights concerning the role of carnitine in the regulation of fuel metabolism in skeletal muscle. The Journal of Physiology, 581, 431-444.

Stephens, F.B., Constantin-Teodosiu, D., Laithwaite, D., Simpson, E.J., \& Greenhaff, P.L. (2006). Insulin stimulates L-carnitine accumulation in human skeletal muscle. The FASEB Journal, 20, 377-379.

Stephens, F.B., Evans, C.E., Constantin-Teodosiu, D., \& Greenhaff, P.L. (2007). Carbohydrate ingestion augments L-carnitine retention in humans. Journal of Applied Physiology (Bethesda, Md.), 102, 1065-1070.

van Loon, L.J.C., Greenhaff, P.L., Constantin-Teodosiu, D., Saris, W.H.M., \& Wagenmakers, A.J.M. (2001). The effects of increasing exercise intensity on muscle fuel utilisation in humans. The Journal of Physiology, 536, 295-304.

Wall, B.T., Stephens, F.B., Constantin-Teodosiu, D., Marimuthu, K., Macdonald, I.A., \& Greenhaff P.L. (2011). Chronic oral ingestion of L-carnitine and carbohydrate increases muscle carnitine content and alters muscle fuel metabolism during exercise in humans. The Journal of Physiology, 589, 963-973. 